\title{
Direct Synthesis with Melt Polycondensation and Microstructure Analysis of Poly(L-lactic acid-co-glycolic acid)
}

\author{
Qinwei GaO, ${ }^{\dagger}$ Ping LAN, Huili SHaO, and Xuechao HU \\ State Key Laboratory for Modification of Fibers and Polymer Materials, \\ College of Material Science and Engineering, Donghua University, Shanghai 200051, China
}

(Received March 26, 2002; Accepted July 6, 2002)

\begin{abstract}
High-molecular-weight poly(L-lactic acid-co-glycolic acid) (PLGA) was prepared through melt polymerization from glycolic acid (GA) and L-lactic acid (L-LA) and then characterized. High resolution ${ }^{1} \mathrm{H}$ and ${ }^{13} \mathrm{C}$ NMR were performed for microstructure analysis of polymer. The solubility in chloroform, compositions, and sequence lengths of PLGA suggest higher reactivity of GA compared with L-LA and shortening GA blocks with reaction time. The racemization of L-LA blocks and transesterification in PLGA are enhanced by increase of GA fractions. PLGA (90/10) samples show crystallization of relatively long L-LA sequences in copolymer chains and the absence of the crystallization of GA blocks. All these results demonstrate the influence of racemization and transesterification on the microstructure of PLGA. KEY WORDS Direct Synthesis / Microstructure / Poly(L-lactic acid-co-glycolic acid) / Poly(L-

lactic acid) / Poly(D, L-lactic acid) /
\end{abstract}

Aliphatic polyesters derived from lactic acid (LA), glycolic acid (GA), and $\varepsilon$-caprolactone (CL) should have promising applications to biodegradable plastic as well as biomedical materials because of their excellent mechanical, processable, biocompatable, and degradable properties. ${ }^{1-4}$ Present in carbohydrate metabolism in nature, LA consists of two optical isomers, L-LA and D-lactic acid (D-LA). The D,L-lactic acid (DLLA) containing equimolar L-LA and D-LA is racemic. Poly(lactic acid) (PLA) with low molecular weight $\left(M_{\mathrm{w}}\right)$ was first prepared by Carothers through the polycondensation of lactic acids ${ }^{5}$ in 1932. Poly(Llactic acid) (PLLA), Poly(D, L-lactic acid) (PDLLA), and Poly(L-lactic acid-co-glycolic acid) (PLGA) can be prepared via both direct synthesis and ring-opening polymerization (ROP). The direct synthesis refers to the polycondensation of LA and/or GA. The ROP refers to the polyaddition of lactides and glycolide, , $^{3,4-14}$ which are prepared by depolymerizing the oligomers of LA and GA. The synthesis and isolation of these lactones cause PLA polymers high-priced, which prevents commodity applications of PLA.

ROP has been preferred to get polymers with high $M_{\mathrm{W}}$ because of the inability of the direct synthesis to increase polymer $M_{\mathrm{w}}$. Thus the direct synthesis has been used to prepare low $M_{\mathrm{w}}$ polymers of hydroxy-acids, which can be used in drug delivery systems. ${ }^{15-21}$ In the direct synthesis of PLLA, poly(glycolic acid) (PGA), and PLGA, factors in the obtain of high $M_{\mathrm{w}}$ polymers consist both in driving the dehydration equilibrium to the direction of esterification and in reducing the depolymerization of PLLA to lactide at high temperature and under vacuum. Since 1995, Ajioka group ${ }^{22,23}$ has developed solution polycondensation of hydroxy-acids, which brought a breakthrough for the direct synthesis. High-molecular-weight PLA and PLGA could be prepared from LA and GA after a relatively long reaction period at $160^{\circ} \mathrm{C}$ under high vacuum in diphenyl ether solution. However, the use of solvents leads to the complexity of process control and the purification of end product, which makes these polymers expensive. The Kimura group has attempted to settle the drawbacks of the solution polycondensation. They prepared high $M_{\mathrm{w}} \mathrm{PLLA}^{24,25}$ and $\mathrm{PGA}^{26}$ through melt and/or melt/solid polycondensation. However, melt polycondensation in the absence of solvent has been hardly performed to prepare high $M_{\mathrm{w}}$ PLGA so far. Moreover, the microstructure analysis of PLLA, PDLLA, and PLGA obtained through melt polymerization has not been performed.

In the present work, melt polymerization was utilized to prepare PLGA with high $M_{\mathrm{w}}$. PDLLA and PLLA samples synthesized by the same process are used as the references of racemization for microstructure analysis of PLGA. The effects of the racemization and transesterification on the polymer crystallinity are discussed.

\section{EXPERIMENTAL}

\section{Materials}

L-LA as a $90 \mathrm{wt} \%$ aqueous solution (PH90, pharmaceutical grade) was purchased from Purac Corp. (Netherland). Aqueous $90 \mathrm{wt} \%$ solution of DL-LA (50/50 molar ratio of L-LA/D-LA), glycolic acid

${ }^{\dagger}$ To whom correspondence should be addressed (Tel: +86-21-62373512, E-mail: Qinway_gao@yahoo.com.cn). 
dihydrate, Tin(II) chloride dihydrate $\left(\mathrm{SnCl}_{2}\right), \quad p$ tolulenesulfonic acid monohydrate (TSA), diethyl ether, Tin powder, chloroform, and molecular sieve (3 $\AA$ ) were purchased from Shanghai Chemical Corp. Molecular sieve was activated at $300^{\circ} \mathrm{C}$. All other reagents were used as received.

\section{Melt Polycondensation of PLGA, PDLLA, and PLLA}

The reaction conditions used in the melt polymerization of PLLA ${ }^{24}$ were employed to prepare PLGA here. A given amount of $90 \mathrm{wt} \%$ aqueous solution of L-LA and GA dihydrate were charged into an $100 \mathrm{~mL}$ threenecked flask, which was equipped with a mechanical stirrer and a reflux condenser packed with molecular sieve ( $3 \AA)$. The LA/GA mixture was first dehydrated into the oligomer, whose degree of polymerization is calculated from ${ }^{1} \mathrm{H}$ NMR to be $6-8$. With the addition of $\mathrm{SnCl}_{2}(0.5 \mathrm{wt} \%$ of the resultant oligomer) and TSA (equimolar to $\mathrm{SnCl}_{2}$ ), the oligomer was gradually heated to $180^{\circ} \mathrm{C}$ under mechanical stirring along with pressure reduced to $1300 \mathrm{~Pa}$ stepwise. Polymerization was maintained under these conditions for $20 \mathrm{~h}$. The obtained product was dissolved in chloroform and subsequently precipitated into diethyl ether. The resulting solids were filtered and then dried under vacuum at $70{ }^{\circ} \mathrm{C}$. Isolated PLGA was kept in a desiccator in the presence of phosphorus pentoxide. PLGA (90/10) was prepared from L-LA/GA $(90 / 10)$ (molar ratio in feed being 90/10), while PLGA (70/30) from L-LA/GA (70/30).

The same process was utilized to prepare PDLLA (50/50) and PLLA-1 from DL-LA and L-LA $90 \mathrm{wt} \%$ aqueous solution respectively. PLLA-2 was prepared from a prepolymer of L-LA $\left(\bar{M}_{\mathrm{n}} 5690\right.$ Daltons) instead of an L-LA oligomer through the melt polymerization. PLLA-1 was a white powder, while PLLA-2 was a slightly yellow to yellow powder. PDLLA (50/50) was a slightly brown powder.

\section{Polymer Characterization}

${ }^{13} \mathrm{C}$ NMR and ${ }^{1} \mathrm{H}$ NMR spectra were carried out at a temperature of $300 \mathrm{~K}$ on a Bruker DMX-500 NMR spectrometer. All polymer samples were dissolved in deuterated chloroform with tetramethylsilane as internal standard. ${ }^{1} \mathrm{H}$ NMR spectra were acquired as $1 \%$ solution at $500 \mathrm{MHz}$, while ${ }^{13} \mathrm{C}$ NMR spectra were acquired at $125 \mathrm{MHz}$, with a pulse angle of $25^{\circ}$, acquisition time of $1.6 \mathrm{~s}$, and a delay time of $10 \mathrm{~s}$. FT-IR spectra were recorded on a MANMNA IR-550 spectrometer (Nicolet Corp.). The samples were examined on $\mathrm{NaCl}$ discs. For each spectrum, 32 scans were taken at a resolution of $4 \mathrm{~cm}^{-1}$.

$\mathrm{X}$-Ray diffraction (XRD) measurements were per- formed with a Rigaku D-MAX/Rb Diffractometer (Rigaku Corporation) with $\mathrm{Cu}-\mathrm{K} \alpha$ radiation at a wavelength of $1.54 \AA$ in the $2 \theta$ range of $5-50^{\circ}$ at $40 \mathrm{kV}$ and $100 \mathrm{~mA}$. The differential scanning calorimetry (DSC) was determined on a DSC2901 thermal analyzer (TA Corp. USA) at a heating rate of $10^{\circ} \mathrm{C} \mathrm{min}^{-1}$. Optical rotation $[\alpha]_{\mathrm{D}}^{25}$ was measured at $25^{\circ} \mathrm{C}$ on a PerkinElmer Md. 243 in an $1 \mathrm{~mL}$ cell of $10 \mathrm{~cm}$ length with the $\lambda$ of $578 \mu$. A sample concentration of $10 \mathrm{~g} \mathrm{~L}^{-1}$ in chloroform was used in all cases.

Molecular weights of polymers were measured by Waters $1525 \mathrm{HPLC}$ at a concentration of $1 \mathrm{mg} \mathrm{mL}^{-1}$ in tetrahydrofuran (THF) with THF as the mobile phase at $1 \mathrm{~mL} \mathrm{~min}^{-1}$. Polymer $M_{\mathrm{w}}$ was calculated by the universal calibration method using polystyrene (Shodex $M_{\mathrm{w}} 10000,30000$, and 60000) as reference. A Waters Styragel (HR 4E, 5E, 6E, Milford MA) column packed with 5-um particles was used to isolate the $M_{\mathrm{w}}$ fractions, detected by a Waters 2410 RI detector.

\section{RESULTS AND DISCUSSION}

\section{Synthesis and Molecular Weights of Copolymers}

According to Kimura, ${ }^{24}$ the $\mathrm{SnCl}_{2}$ /TSA catalyst system $(\mathrm{Sn}(\mathrm{II}) / \mathrm{TSA})$ is effective for increasing $M_{\mathrm{w}}$ of PLLA and preventing discoloration and racemization of PLLA in melt polymerization. Thus the Sn(II)/TSA catalyst system was used in the present work to prepare PLGA, PLLA, and PDLLA with melt polycondensation in the absence of solvent. The FT-IR spectra of PLLA, PDLLA, and PLGA are given in Figure 1. The spectra of PLLA and PDLLA show a welldefined absorption at $1755 \mathrm{~cm}^{-1}$ due to the ester carbonyl, peaks at $1200-1000 \mathrm{~cm}^{-1}$ to the $\mathrm{C}-\mathrm{O}$ stretch, and peaks at $2850-2960 \mathrm{~cm}^{-1}$ to the stretch of $\mathrm{CH}$ and $\mathrm{CH}_{3}$ groups. ${ }^{16,27,28}$ The wide band at $3300 \mathrm{~cm}^{-1}$ owing to hydrogen-bonded $\mathrm{OH}$ groups denotes the existence of $\mathrm{OH}$ end groups in polymer chains. PLGA spectrum is similar to that of PLLA except for a medium band at $2926 \mathrm{~cm}^{-1}$ due to $\mathrm{CH}_{2}$ of GA in the L-LA/GA copolymer.

Solubility in chloroform, $M_{\mathrm{w}}$, compositions, and yields of polymers were detected. All results are given in Table I. All L-LA/GA oligomers are soluble in chloroform. PLGA solubility decreases with reaction time, and PLGA becomes insoluble after the oligomer polymerized for $6 \mathrm{~h}$. With further reaction time, the solubility of PLGA increases again, and PLGA becomes soluble eventually. PLGA solubility decreases with GA content in polymers. Poly(glycolide) and copolymers of glycolide with long glycolide blocks are usually insoluble in most common solvents including chloroform. PLGA solubility indicates higher reactivity of 
Table I. The results of PLLA, PLGA, and PDLLA prepared by the direct synthesis through melt polymerization

\begin{tabular}{|c|c|c|c|c|c|c|c|}
\hline Samples & $\frac{\bar{M}_{\mathrm{n}}^{\mathrm{a}}}{k \mathrm{Da}}$ & $\mathrm{MWD}^{\mathrm{a}}$ & $\frac{f_{\mathrm{G}}^{\mathrm{b}}}{\%}$ & $\frac{F_{\mathrm{G}}{ }^{\mathrm{b}}}{\%}$ & $\frac{\text { Yield }^{\mathrm{c}}}{\%}$ & Solubility $^{\mathrm{d}}$ & Appearance \\
\hline PLLA-1 & 23.6 & 1.31 & 0 & 0 & 53.82 & +++ & White powder \\
\hline PLLA-2 & 31.4 & 1.40 & 0 & 0 & 51.21 & +++ & Slight yellow powder \\
\hline PLGA (90/10) & 54.7 & 1.28 & 10.0 & 12.12 & 45.44 & ++ & White fibril \\
\hline PLGA-1 $(90 / 10)^{\mathrm{e}}$ & 25.2 & 1.29 & 10.0 & 13.80 & 44.83 & ++ & White powder \\
\hline PLGA (70/30) & 25.5 & 1.75 & 30.0 & 32.20 & 42.64 & + & Yellow solid \\
\hline PDLLA $(50 / 50)$ & 18.0 & 1.30 & 0.0 & 0 & 40.20 & ++++ & Slight brown powder \\
\hline
\end{tabular}

${ }^{\mathrm{a}} \bar{M}_{\mathrm{n}}$ calculated from GPC. Da is the abbreviation of dalton. Molecular weight distribution (MWD) is equal to $\bar{M}_{\mathrm{W}} / \bar{M}_{\mathrm{n}} \cdot{ }^{\mathrm{b}} f_{\mathrm{G}}$ and $F_{\mathrm{G}}$ were molar fractions of GA in feed and in copolymers respectively. $F_{\mathrm{G}}$ was calculated from ${ }^{1} \mathrm{H}$ NMR spectra. ${ }^{c}$ Yield $(\%)$ of polymers were calculated by the ratio of isolated polymer to initially charged reagents. ${ }^{\mathrm{d}}$ Solubility in chloroform of polymers decreased from ++++ to + . ${ }^{\mathrm{e}}$ PLGA-1 (90/10), copolymer prepared after the oligomer of L-LA/GA (90/10) was polymerized for $12 \mathrm{~h}$.

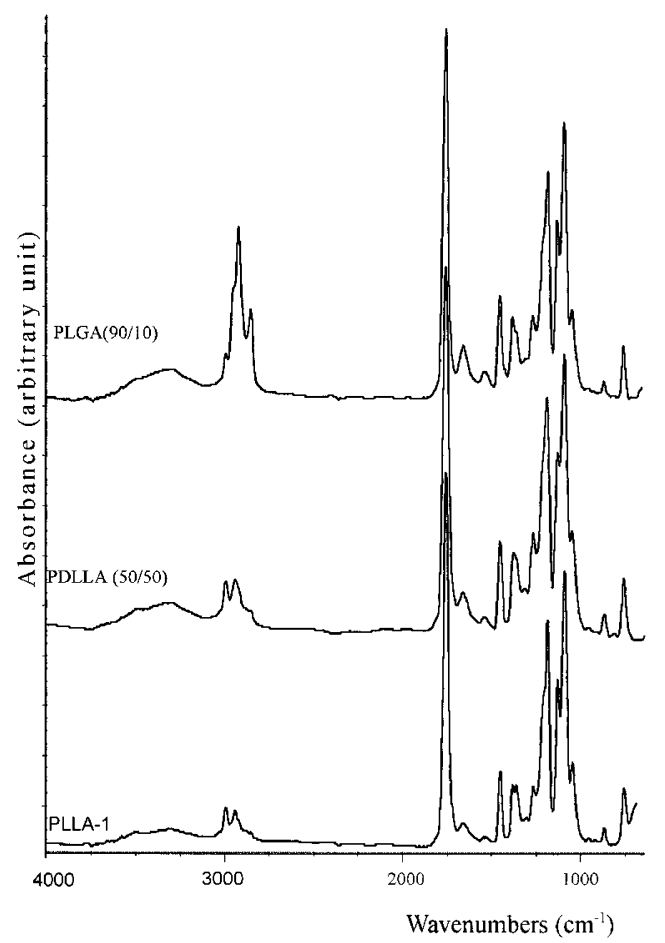

Figure 1. FT-IR spectra of PLLA, PDLLA (50/50), and PLGA (see the text).

GA in comparison with L-LA. Thus in the L-LA/GA copolymerization, GA can be polymerized preferentially, leading to the formation of long GA blocks. With longer polymerization time, L-LA will be built in polymer chains when GA is depleted, which can increase the solubility of PLGA. Thus L-LA and GA monomers are not randomly incorporated in polymer chains, as observed in the ring-opening copolymerization of lactide and glycolide. ${ }^{1,2,8,13}$ ROP at high temperature and high vacuum results in the racemization of L-lactide units and transesterification, which increase with initiator basicity, reaction time, and reaction temperature. ${ }^{6}$ Similarly at high temperature and vacuum, melt polycondensation of PLGA can also induce the racemization of L-LA units and transesterification. The transes-

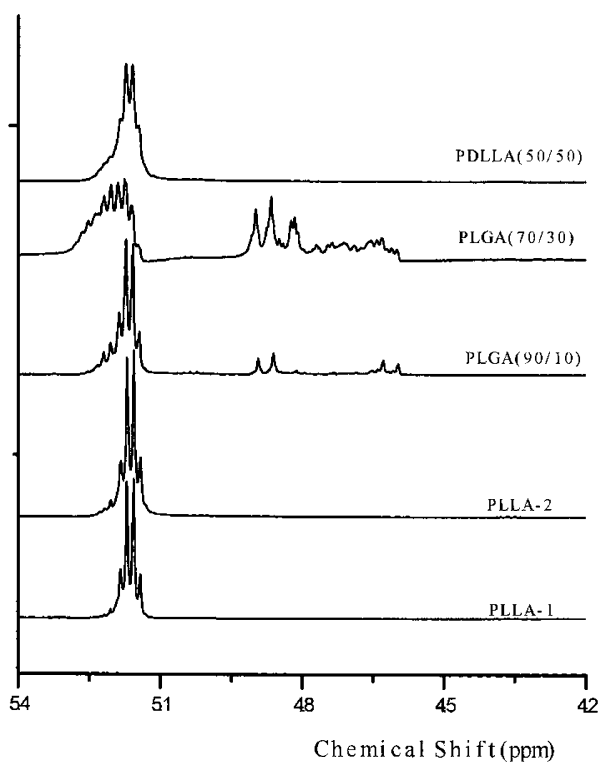

Figure 2. ${ }^{1} \mathrm{H}$ NMR spectra $(500 \mathrm{MHz})$ of PLLA, PDLLA (50/50), and PLGA (methine region in LA and methene region in $\mathrm{GA}$ ) obtained in $\mathrm{CDCl}_{3}$ solutions.

terification will reduce both GA and LA block lengths gradually, which will promote PLGA solubility and lower PLGA crystallinity.

The number average molecular weight $\left(\bar{M}_{\mathrm{n}}\right)$ and molecular weight distribution (MWD) of the polymers were detected through GPC (shown in Table I). PLGA (90/10) with the highest $M_{\mathrm{w}}$ among these polymers shows a narrow MWD. MWD of PLGA increases with GA fractions and decreases slightly with reaction time. The compositions of PLGA were determined by ${ }^{1} \mathrm{H}$ NMR spectra. Figure 2 gives typical methine regions in the ${ }^{1} \mathrm{H}$ NMR spectra of PLLA, PDLLA, and PLGA samples. The molar fraction of GA moiety in PLGA can be calculated from the integrated area of peaks at $5.15 \mathrm{ppm}$ due to methine protons in LA units ${ }^{17,29,30}$ and that of peaks at $4.60-4.90 \mathrm{ppm}$ owing to methylene protons in GA blocks in PLGA. ${ }^{7,9,15}$ Assigning $I_{\mathrm{L}}$ to integrated peak area at $5.15 \mathrm{ppm}, I_{\mathrm{G}}$ integrated 
Table II. Crystallinities and sequence lengths of copolymers prepared by the direct synthesis through melt polymerization

\begin{tabular}{|c|c|c|c|c|c|c|c|c|}
\hline \multirow{2}{*}{ Samples } & \multirow{2}{*}{$\frac{F_{\mathrm{G}}{ }^{\mathrm{a}}}{\%}$} & \multirow{2}{*}{$\frac{T_{\mathrm{g}}}{{ }^{\circ} \mathrm{C}}$} & \multirow{2}{*}{$\frac{T_{\mathrm{m}}}{{ }^{\circ} \mathrm{C}}$} & \multirow{2}{*}{$\frac{\text { Crystallinity }^{\mathrm{b}}}{\%}$} & \multirow{2}{*}[\alpha]{$_{\mathrm{D}}^{25}$} & \multirow{2}{*}{$\frac{\text { Racemization }^{\mathrm{c}}}{\%}$} & \multicolumn{2}{|c|}{ Average block lengths } \\
\hline & & & & & & & $L_{\mathrm{L}}$ & $L_{\mathrm{G}}$ \\
\hline PLLA-1 & 0 & 58.4 & 155.7 & 57.69 & -146 & 6.76 & - & - \\
\hline PLLA-2 & 0 & 58.2 & 149.6 & 38.71 & -132 & 19.40 & - & - \\
\hline PLGA-1 $(90 / 10)^{d}$ & 13.80 & $\mathrm{ND}^{\mathrm{e}}$ & ND & ND & -131 & 25.82 & 17.52 & 2.84 \\
\hline PLGA (90/10) & 12.12 & 57.1 & 116.3 & 28.48 & -125 & 29.31 & 17.47 & 2.40 \\
\hline PLGA (70/30) & 32.20 & 52.8 & ND & ND & -112 & 48.84 & 5.45 & 2.60 \\
\hline PDLLA $(50 / 50)$ & 0 & 48.4 & 104.8 & 14.05 & -58 & 40.00 & - & - \\
\hline
\end{tabular}

${ }^{\mathrm{a}} F_{\mathrm{G}}$, molar fraction of GA in copolymers, calculated from ${ }^{1} \mathrm{H}$ NMR. ${ }^{\mathrm{b}}$ Calculated from DSC curve according to ref 45. ${ }^{\mathrm{c} C a l c u l a t e d}$ from carbonyl signals in ${ }^{13} \mathrm{C}$ NMR spectra. ${ }^{\mathrm{d}}$ PLGA-1 (90/10), prepared from the oligomer of L-LA/GA (90/10) after polymerized for $12 \mathrm{~h} .{ }^{\mathrm{e}} \mathrm{ND}$, not detected.

peak area of at 4.6-4.9 ppm, and $F_{\mathrm{G}}$ molar fraction of GA respectively, $F_{\mathrm{G}}$ can be calculated according to the following relationships, $F_{\mathrm{G}}=I_{\mathrm{G}} /\left(2 I_{\mathrm{L}}+I_{\mathrm{G}}\right)$. The molar fraction of GA in PLGA is higher than that in the monomer feed, even though it decreases with reaction time as shown in Table I. GA fractions indicate that GA has higher reactivity than L-LA, which is consistent with that of the PLGA solubility.

\section{Racemization and Sequence Length of PLGA}

The microstructures of polyester chains appear to affect biodegradable and mechanical properties of polymers. The microstructures of copolyesters are influenced by the kind of monomer, initiator and transesterification in the ROP. In Figure 2, the methine region at $5.15 \mathrm{ppm}$ of PDLLA (50/50) shows two indistinctly resolved quartets caused by racemic LA units, which is similar to poly(D, L-lactide) with more or less racemic structure. ${ }^{17,30}$ In comparison with PDLLA (50/50), PLLA-1 spectrum shows a less intense quartet in down-field at the methine region because of slight racemization of L-LA units. Because of long reaction time, PLLA-2 shows more racemization than PLLA-1. PLGA samples with $\mathrm{CH}$ signals similar to those of PDLLA possess more racemic structure than PLLA-2. The racemization of PLGA increases greatly with GA fractions. The optical rotation of the obtained polymers decreases with prolonged reaction time and increasing GA fractions in the copolymers as shown in Table II. All these results indicate that the addition of GA increases the racemization of LA blocks. $\mathrm{CH}_{2}$ signals of PLGA in Figure 2 appear as a nineline multiplet attributed to various pentads, whose intensity is greatly affected by the transesterification in poly(lactide-co-glycolide). ${ }^{7,9,15}$ In the melt polymerization of PLLA with Sn(II)/TSA as catalyst, ${ }^{24}$ terminal groups of PLLA are coordinated with the catalyst center of Sn(II). TSA as a ligand fills the open coordination sites of the catalyst, so side reaction leading to the discoloration and racemization of PLLA is pre- vented. In L-LA/GA copolymerization, GA terminal groups with higher reactivity could be coordinated with the catalyst preferentially. Thus the coordination of LLA and TSA could be hindered to increase side reaction. Consequently, racemization and discoloration of PLGA increase with GA fractions.

High-resolution ${ }^{13} \mathrm{C}$ NMR spectroscopy has been successfully used to characterize the microstructures of homo- and copolymers derived from L-LA, ${ }^{17}$ GA, ${ }^{18}$ lactides,${ }^{8,27}$ glycolide, ${ }^{6,7}$ and CL. ${ }^{31-36}$ Carbonyl signals are more suitable to analyze monomer block lengths in copolymers, because they are more sensitive to sequence effect than other signals such as methyl, methylene, and methine. ${ }^{8,18,34}$ The methine signals at $68.5-69.5 \mathrm{ppm}$ are useful for determination of the racemization of PDLLA and PLLA. ${ }^{34,37}$ Carbonyl positions of L-LA and GA blocks are shown in Figure 3. Figure 4 shows the carbonyl regions at $165-170 \mathrm{ppm}$ of the ${ }^{13} \mathrm{C}$ NMR spectra of the obtained polymers. Assignments of signals due to the isotactic (i) and syndiotactic (s) sequences of the lactate units are shown in Figure 4 according to the literature. ${ }^{24,38-41}$ The degree of racemization of polymer was calculated from the integral ratio of these sequence signals (see Table II). PDLLA (50/50) spectrum shows predominantly isotactic polymer chains with racemization of $40.0 \%$, which is much different from that of poly(D,L-lactide) prepared by ROP process. ${ }^{34,37}$ PDLLA (50/50) is optically active, levorotary, i.e., with predominant L-LA units. PDLLA prepared from DL-LA with tin powder as catalyst or without a catalyst is racemic. ${ }^{17,18,21,22}$ This means that $\mathrm{L}$ enantiomer is preferentially polymerized by $\mathrm{Sn}(\mathrm{II}) / \mathrm{TSA}$ catalyst in the present conditions. Thus stereoselective polymerization of DL-LA exists, as in the case of D,L-lactide reported by Spassky. ${ }^{38}$

Carbonyl carbon signals in the ${ }^{13} \mathrm{C}$ NMR spectra of PLGA were designated in comparison with those of PLLA, PDLLA, and poly(L-lactide- $c o$-glycolide) ${ }^{6-9,18}$ In PLGA spectra, a new peak at 169.44 ppm appears and increases with GA fractions, which results 
<smiles>CCOC(C)C(C)=O</smiles><smiles>COCC(C)=O</smiles><smiles>COC(C)C(=O)[AlH2]</smiles><smiles>CCOC(C)C(=O)Cl</smiles><smiles>COC(C)C(=O)O</smiles><smiles>COC(C)C([14CH3])=O</smiles>

Figure 3. Labeling of different carbonyl units of poly(L-lactic acid-co-glycolic acid).

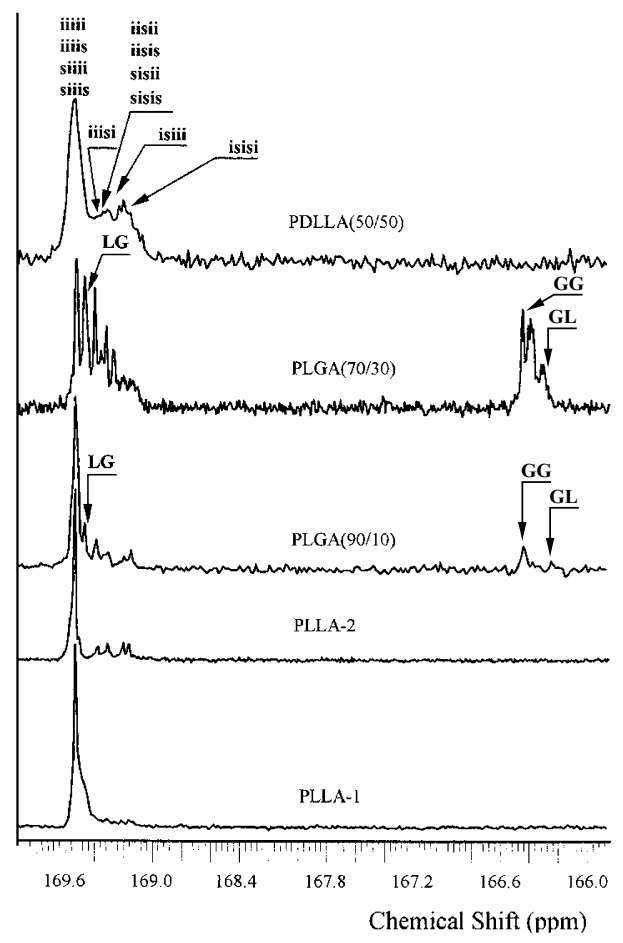

Figure 4. ${ }^{13} \mathrm{C}$ NMR spectra $(125 \mathrm{MHz})$ of PLLA, PDLLA (50/50), PLGA (carbonyl region) obtained in $\mathrm{CDCl}_{3}$ solutions.

from LG blocks. The intensity of carbonyl signals due to the racemic units in PLGA increases with GA fractions. Racemization of PLGA indicates that the racem-

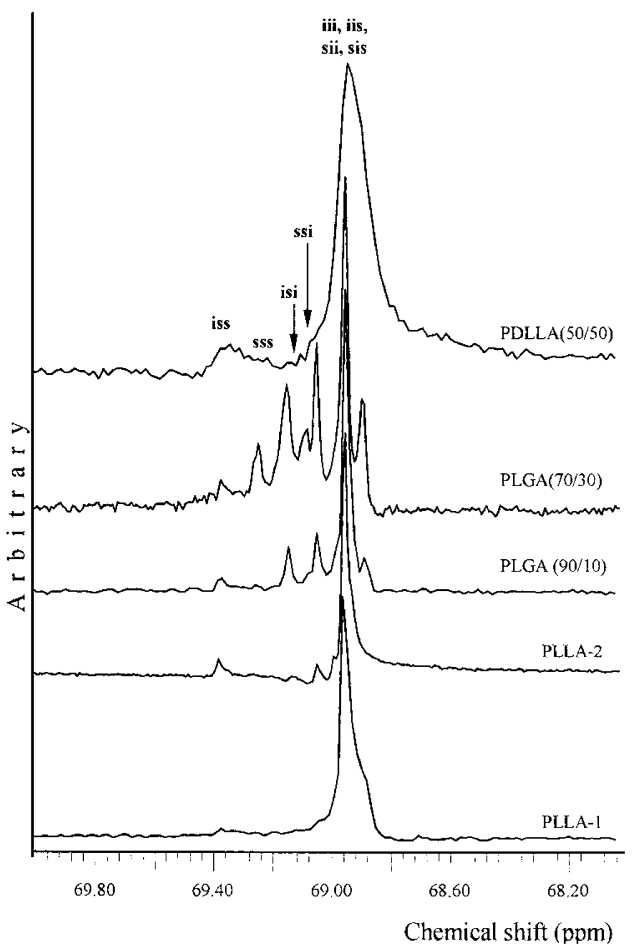

Figure 5. ${ }^{13} \mathrm{C}$ NMR spectra $(125 \mathrm{MHz})$ of PLLA, PDLLA, PLGA (methine region) obtained in $\mathrm{CDCl}_{3}$ solutions.

ization of LA blocks increases with GA fraction and reaction time. Racemization makes it complicated to determine signal assignments of PLGA accurately.

Methane signals at $68.5-69.5 \mathrm{ppm}$ in Figure 5 are designated in comparison with poly(D, L-lactide) and poly(L-lactide)..$^{34,37}$ The spectrum of PLLA-2 shows more intense signals due to tetrads such as iss, sss, isi, and ssi than that of PLLA-1, which confirms the effect of reaction time on the PLLA racemization. The PDLLA spectrum with a strong signal at $68.94 \mathrm{ppm}$ due to tetrads of iii, iis, sii, and sis indicates stereoselective polymerization of DL-LA, which is consistent with the above results. The intensities of peaks due to iss, sss, isi, and ssi increase greatly with GA contents, which is further evidence of promoted racemization of LA blocks in the presence of GA. A new peak at $68.84 \mathrm{ppm}$ can be caused by GA block, because it appears and increases with increasing GA fractions in PLGA.

Carbonyl signals of GA block at $166.40 \mathrm{ppm}$ show two peaks attributed to GG and GL units respective$1 y^{6-9,18}$ (see Figure 4). From intensity ratios of the two carbonyl signals, the average lengths of GA blocks $\left(L_{\mathrm{G}}\right)$ and L-LA blocks $\left(L_{\mathrm{L}}\right)$ were calculated according to the eq 1. All results are shown in Table II. $L_{\mathrm{G}} / L_{\mathrm{L}}$ can be checked by the ${ }^{1} \mathrm{H}$ NMR spectroscopically determined composition served as control, according to eq $2 .^{6-9,18}$

$$
L_{\mathrm{L}}=\frac{I_{\mathrm{LL}}+I_{\mathrm{LG}}}{I_{\mathrm{LG}}} \quad L_{\mathrm{G}}=\frac{I_{\mathrm{GG}}+I_{\mathrm{GL}}}{I_{\mathrm{GL}}}
$$




$$
\frac{n_{\mathrm{G}}}{n_{\mathrm{L}}}\left({ }^{1} \mathrm{HNMR}\right)=\frac{L_{\mathrm{G}}}{L_{\mathrm{L}}}\left({ }^{13} \mathrm{C} \mathrm{NMR}\right)
$$

Where $n_{\mathrm{L}}$ and $n_{\mathrm{G}}$ are the LA and GA molar fraction in the copolymers respectively. $n_{\mathrm{L}} / n_{\mathrm{G}}\left({ }^{1} \mathrm{H} \mathrm{NMR}\right)$ is in fair agreement with $L_{\mathrm{G}} / L_{\mathrm{L}}\left({ }^{13} \mathrm{C} \mathrm{NMR}\right)$, which supports the validity of each signal intensity. The random copolymers of L-LA/GA may possess random sequences with $L_{\mathrm{G}}$ near to 1 . From the lengths of L-LA and GA blocks, the present reaction conditions obviously bring out a sequential block copolymer of L-LA/GA instead of a random copolymer. Both $L_{\mathrm{L}}$ and $L_{\mathrm{G}}$ decrease with reaction time in PLGA (90/10). $L_{\mathrm{L}}$ decreases with GA fractions in PLGA, while $L_{\mathrm{G}}$ increases. Considering the solubility and ${ }^{1} \mathrm{H}$ NMR spectra of PLGA, it is reasonable that transesterification and differences of reactivity between LA and GA exist in the melt copolymerization. The copolymerization of L-lactide with CL or glycolide ${ }^{1,2}$ has shown similar results. The lengths of the GA and LA blocks in copolymers decrease continuously, and may be equilibrated eventually by the transesterification.

\section{Crystallinity of Copolymers}

Figure 6 gives typical DSC thermograms of the polymers obtained. PLLA- 1 curve shows a glass transfer temperature $\left(T_{\mathrm{g}}\right)$ at $58.4{ }^{\circ} \mathrm{C}$ and an endothermic peak due to the crystal fusion at the melting temperature $\left(T_{\mathrm{m}}\right)$ of $155.7^{\circ} \mathrm{C} . T_{\mathrm{m}}$ of PLLA-1 is relatively lower than that of poly(L-lactide) $\left(T_{\mathrm{m}} 175^{\circ} \mathrm{C}\right)$ prepared by ROP. ${ }^{28,35}$ The lower $T_{\mathrm{m}}$ results from low crystallinity and imperfect crystallization of PLLA, caused by some racemic sequences in PLLA chains. PLLA-2 with higher racemization shows lower $T_{\mathrm{m}}$ than PLLA1. The enthalpy of fusion for a large crystal of poly(Llactide) with infinite size corresponds to $93 \mathrm{~J} \mathrm{~g}^{-1} .42$ In the present research, the crystallinity of PLLA-1 was $57.69 \%$, similar to PLLA reported by Kimura. ${ }^{24}$ Racemization of PLLA can be made sure on the basis of the relation between melting temperature and racemic content of poly(L-lactide). ${ }^{43}$

Poly(D, L-lactide) prepared via ROP is amorphous ( $T_{\mathrm{g}}$ at $45-55^{\circ} \mathrm{C}$ and no $\left.T_{\mathrm{m}}\right),{ }^{35}$ while PDLLA $(50 / 50)$ in the present work shows $T_{\mathrm{g}}$ at $48.4^{\circ} \mathrm{C}, T_{\mathrm{m}}$ at $104.8^{\circ} \mathrm{C}$, and crystallinity of $14.05 \%$. The partial crystallization of PDLLA $(50 / 50)$ can be caused by stereoselective polymerization, which is consistent with ${ }^{1} \mathrm{H}$ and ${ }^{13} \mathrm{C}$ NMR spectral analysis and optical rotation. Neat poly(glycolide) is substantially crystalline material with $T_{\mathrm{m}}$ of $222^{\circ} \mathrm{C}$ and small $T_{\mathrm{g}}$ at $45^{\circ} \mathrm{C}$, while poly (glycolide-co-L-lactide) with $12.3 \%$ glycolide units showed $T_{\mathrm{m}}$ at $166.4^{\circ} \mathrm{C}$ and $T_{\mathrm{g}}$ at $40.4^{\circ} \mathrm{C} .{ }^{8,12,13}$ In the present work, PLGA $(90 / 10)$ with $12.12 \%$ GA units shows $T_{\mathrm{g}}$ at $57.1^{\circ} \mathrm{C}, T_{\mathrm{m}}$ at $116.3^{\circ} \mathrm{C}$,

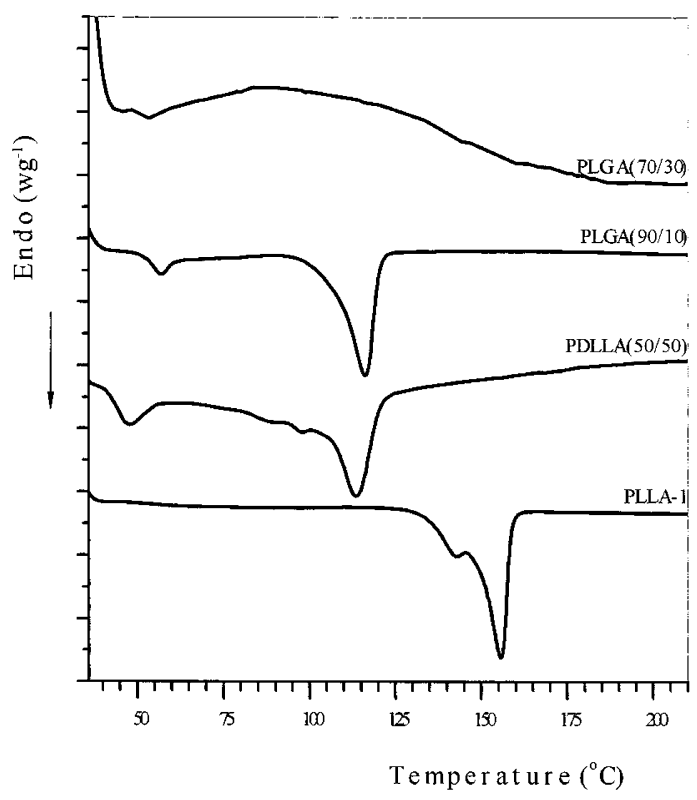

Figure 6. DSC thermograms of PLLA-1, PDLLA (50/50), and PLGA (see the text).

and crystallinity of $28.48 \%$ according to PLLA. ${ }^{42}$ The crystallization of PLGA chains yields smaller and less perfect crystallites, because the crystal lattice of L-LA blocks tends to exclude GA units, and incorporation causes lattice defects. When the molar fraction of GA in feed is more than $20 \%$, the amorphous copolyester is formed because crystallization is reduced by the decrease of the L-LA block length. Additionally, the racemization promoted by the addition of glycolic acid monomer could also perform important role on the decrease of $T_{\mathrm{m}}$ and crystallinity of PLGA. ${ }^{6}$ Thus DSC measurements show good agreement with NMR sequence analysis.

X-Ray diffractograms of the obtained polymers are given in Figure 7. The diffraction curve of PLLA1 shows a sharp and intense peak at 16.84 degree $2 \theta$ due to 020 reflection. Other peaks can be observed at $14.90,19.21$, and 22.45 degree $2 \theta$ due to $101,023,121$ reflection respectively. ${ }^{15,18,28,44,45}$ These values coincide with observed values of the $\alpha$ structure of poly(Llactide). PGA with $\bar{M}_{\mathrm{n}}$ of 2900 prepared by direct synthesis shows reflections at $2 \theta$ of $22.2^{\circ}$ and $28.9^{\circ} .{ }^{15}$ The diffraction spectrum of PLGA (90/10) consists of a relatively intense reflection at 16.84 degree $2 \theta$ and two less resolved peaks at $14.90,19.21$ degree $2 \theta$ due to the crystallization of L-LA sequences, but no crystallization of GA sequences can be detected. The crystallization of PLGA (90/10) indicates the presence of relatively long LA sequences in the polymer chains, as confirmed by ${ }^{13} \mathrm{C}$ NMR analysis. PLGA (70/30) becomes amorphous, because the length of L-LA blocks is lessened by increasing GA content through transesterification. All results are consistent with those of ${ }^{1} \mathrm{H}$ 
Q. GAO et al.

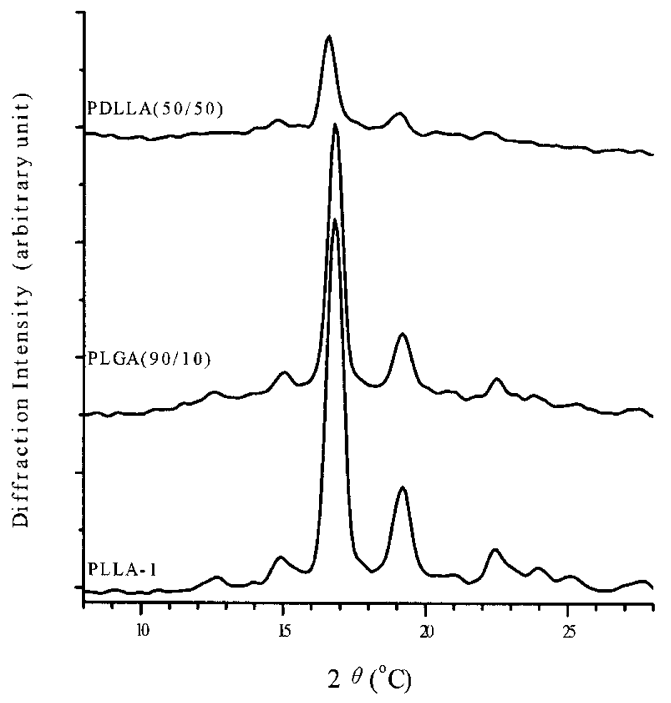

Figure 7. X-Ray diffractogram of PLLA-1, PDLLA (50/50), and PLGA (90/10).

NMR, ${ }^{13} \mathrm{C}$ NMR, and DSC determinations.

\section{CONCLUSION}

Direct synthesis was utilized to prepare PLLA, PDLLA, and PLGA with high $M_{\mathrm{w}}$ and narrow MWD through melt polycondensation in the presence of $\mathrm{Sn}(\mathrm{II}) / \mathrm{TSA}$ catalyst system. In the copolymerization of L-LA with GA, the reactivity of GA is higher than that of L-LA. The solubility in chloroform of PLGA decreases with GA content in feed, while the racemization of copolymers is promoted by increasing GA fractions. PDLLA (50/50) displays predominantly isotactic polymer chains because of partial stereoselective polymerization of racemic DL-LA. Transesterification occurs in the copolymerization of L-LA with GA, which lessens the sequence length of GA and L-LA. Racemization and transesterification result in short sequence length and lower crystallinity, as verified by DSC and XRD measurements. Present reaction conditions bring out sequential block copolymers instead of random copolymers of L-LA/GA.

\section{REFERENCES}

1. D. W. Grijpma, G. J. Zondervan, and A. J. Pennings, Polym. Bull., 25, 327 (1991).

2. D. W. Grijpma and A. J. Pennings, Polym. Bull., 25, 335 (1991).

3. G. Chen, T. Ushida, and T. Tateishi, Biomaterials, 22, 2563 (2001).

4. M. Dunne, O. I. Corrigan, and Z. Ramtoola, Biomaterials, 21, 1659 (2000).

5. W. H. Carothers, G. L. Dorough, and F. J. Van Na, J. Am. Chem. Soc., 54, 761 (1932).

6. H. R. Kricheldorf and I. Kreiser, Makromol. Chem., 188, 1861
(1987).

7. J. Kasperczyk, Polymer, 37, 201 (1996).

8. D. W. Grijpma, A. J. Nijenhuis, and A. J. Pennings, Polymer, 31, 2201 (1990).

9. S. M. F. Farnia, J. Mohammadi-Rovshandeh, and M. N. Sarabolouki, J. Appl. Polym. Sci., 73, 633 (1999).

10. D. D. Hile and M. V. Pishko, Makromol. Rapid Commun., 20, 511 (1999).

11. D. D. Hile and M. V. Pishko, J. Polym. Sci., Part A: Polym. Chem., 39, 562 (2001).

12. D. Cohn, H. Younes, and G. Marom, Polymer, 28, 2018 (1987).

13. D. K. Gilding and A. M. Reed, Polymer, 20, 1459 (1979).

14. D. K. Gilding and A. M. Reed, Polymer, 22, 494 (1981).

15. H. Fukuzaki, M. Yoshida, M. Asano, Y. Aiba, and M. Kumakura, Eur. Polym. J., 26, 457 (1990).

16. N. Wang, X. S. Wu, H. Lujian-Upton, E. Donahue, and A. Siddiqui, Polym. Mater. Sci. Eng., 76, 373 (1997).

17. J. L. Espartero, I. Rashkov, S. M. Li, N. Manolova, and M. Vert, Macromolecules, 29, 3535 (1996).

18. H. Fukuzaki, M. Yoshida, M. Asano, and Y. Aiba, Eur. Polym. J., 24, 1029 (1988).

19. K. Imasaka, T. Nagai, M. Yoshida, H. Fukuzaki, M. Asano, and M. Kumakura, Eur. Polym. J., 26, 831 (1990).

20. K. Imasaka and T. Nagai, Makromol. Chem., 191, 2077 (1990).

21. H. Fukuzaki, M. Yoshida, M. Asano, and M. Kumakura, Eur. Polym. J., 25, 1019 (1989).

22. M. Ajioka, K. Enomoto, K. Suzuki, and A. Yamaguchi, Bull. Chem. Soc. Jpn., 68, 2125 (1995).

23. M. Ajioka, K. Suizu, C. Higuchi, and T. Kashima, Polym. Degrad. Stab., 59, 137 (1998).

24. S. I. Moon, C. W. Lee, M. Miyamoto, and Y. Kimura, J. Polym. Sci., Part A: Polym. Chem., 38, 1673 (2000).

25. S. I. Moon, C. W. Lee, I. Taniguchi, M. Miyamoto, and Y. Kimura, Polymer, 42, 5059 (2001).

26. K. Takahashi, I. Taniguchi, M. Miyamoto, and Y. Kimura, Polymer, 41, 8725 (2000).

27. Von R. C. Schukz and J. Schaab, Makromol. Chem., 87, 90 (1965).

28. T. Miyata and T. Masuko, Polymer, 39, 5515 (1998).

29. E. J. Choi, J. K. Park, and H. N. Chang, J. Polym. Sci., Part B. Polym. Phys., 32, 2481 (1994).

30. A. Schindler and D. Harper, J. Polym. Sci., Polym. Lett. Ed., 14, 72 (1976).

31. J. Kasperczyk and M. Bero, Makromol. Chem., 194, 913 (1993).

32. M. Bero, J. Kasperczyk, and G. Adamus, Makromol. Chem., 194, 907 (1993).

33. J. Kasperczyk and M. Bero, Makromol. Chem., 192, 1777 (1991).

34. M. Bero, J. Kasperczyk, and Z. J. Jedlinski, Makromol. Chem., 191, 2287 (1990).

35. P. Vanhoorne, Ph. Dubois, R. Jerome, and P. Teyssie, Macromolecules, 25, 37 (1992).

36. E. Lillie and R. C. Schulf, Makromol. Chem., 176, 1901 (1975).

37. Z. Jedlinski and W. Walach, Makromol. Chem., 192, 2051 (1991). 
38. N. Spassky, M. Wisniewski, C. Pluta, and A. L. Borgne, Macromol. Chem. Phys., 197, 2627 (1996).

39. J. Coudane, C. U. Peyret, G. Schwach, and M. Vert, J. Polym. Sci., Part A: Polym. Chem., 35, 1651 (1997).

40. F. Chabot, M. Vert, S. Chapelle, and P. Granger, Polymer, 24, 53 (1983).

41. K. A. M. Thakur, P. T. Kean, E. S. Hall, J. J. Kolstad, T. A. Lindgren, M. A. Doscotch, J. I. Siepmann, and E. J. Munson, Macromolecules, 30, 2422 (1997).
42. E. W. Fischer, H. J. Sterzel, and G. Wegner, Kolloid-Z. u. Z. Polymere, 251, 980 (1973).

43. H. R. Kricheldorf, C. Boettcher, and K. U. Tonnes, Polymer, 33, 2817 (1992).

44. D. Brizzolara and H.-J. Cantow, Macromolecules, 29, 191 (1996).

45. W. Hoogsteen, A. R. Postema, A. J. Pennings, G. Ten Brinke, and P. Zugenmaier, Macromolecules, 23, 634 (1990). 